\title{
Instrumented figure skating blade for measuring on-ice skating forces
}

\author{
S A. Acuña \\ Brigham Young University - Provo \\ D M. Smith \\ Brigham Young University - Provo \\ J M. Robinson \\ Brigham Young University - Provo \\ J C. Hawks \\ Brigham Young University - Provo \\ P Starbuck \\ Follow this and additional works at: https://scholarsarchive.byu.edu/facpub \\ Part of the Exercise Science Commons \\ See next page for additional authors

\section{Original Publication Citation} \\ Acuña, S, Smith, D, Robinson, J, Hawks, J, Starbuck, P, King, D, Ridge, S, and Charles, S. (2014). \\ Instrumented figure skating blade for measuring on-ice skating forces. Measurement Science \\ and Technology, 25(12). http://dx.doi.org/10.1088/0957-0233/25/12/125901
}

\section{BYU ScholarsArchive Citation}

Acuña, S A.; Smith, D M.; Robinson, J M.; Hawks, J C.; Starbuck, P; King, D L.; Ridge, Sarah T.; and Charles, Steven Knight, "Instrumented figure skating blade for measuring on-ice skating forces" (2014). Faculty Publications. 2015.

https://scholarsarchive.byu.edu/facpub/2015

This Peer-Reviewed Article is brought to you for free and open access by BYU ScholarsArchive. It has been accepted for inclusion in Faculty Publications by an authorized administrator of BYU ScholarsArchive. For more information, please contact ellen_amatangelo@byu.edu. 


\section{Authors}

S A. Acuña, D M. Smith, J M. Robinson, J C. Hawks, P Starbuck, D L. King, Sarah T. Ridge, and Steven Knight Charles 


\title{
Instrumented figure skating blade for measuring on-ice skating forces
}

S A Acuña, D M Smith, J M Robinson, J C Hawks, P Starbuck, D L King, S T Ridge and S K Charles

\begin{abstract}
Competitive figure skaters experience substantial, repeated impact loading during jumps and landings. Although these loads, which are thought to be as high as six times body weight, can lead to overuse injuries, it is not currently possible to measure these forces on-ice. Consequently, efforts to improve safety for skaters are significantly limited. Here we present the development of an instrumented figure skating blade for measuring forces on-ice. The measurement system consists of strain gauges attached to the blade, Wheatstone bridge circuit boards, and a data acquisition device. The system is capable of measuring forces in the vertical and horizontal directions (inferior-superior and anterior-posterior directions, respectively) in each stanchion with a sampling rate of at least $1000 \mathrm{~Hz}$ and a resolution of approximately one-tenth of body weight. The entire system weighs $142 \mathrm{~g}$ and fits in the space under the boot. Calibration between applied and measured force showed excellent agreement $(R>0.99)$, and a preliminary validation against a force plate showed good predictive ability overall ( $R \geq 0.81$ in vertical direction). The system overestimated the magnitude of the first and second impact peaks but detected their timing with high accuracy compared to the force plate.
\end{abstract}

Keywords: figure skating boot, force, dynamics, kinetics, instrumentation, on-ice

\section{Introduction}

Competitive figure skaters must master and maintain the most difficult jumps to achieve success in international competition. Many skaters practice up to five days a week, year round, performing 50-100 jumps each day [1] . Repetitive impacts of jump landings impose stress on the body, which without sufficient recovery can lead to overuse injuries [2]. These stresses depend largely on the impact forces with the ice. However, due to technological challenges, limited data are available about the impact forces that skaters experience.

Simulated take-off and landings have been conducted off-ice, suggesting force magnitudes of up to six times body weight [1], but with differences in take-off velocities, angular momentum, landing surfaces, and proper technique, on-ice jumps likely have different loading responses. Lockwood and Gervais measured on-ice impact forces using pressure-sensitive insoles []ㅡ, but such insoles only measure pressure and normal force. Non-normal forces may be substantial in skating due to the large angles between the blade and ice during take-off and landing. Forces have been measured during other on-ice sports, specifically speed skating and ice hockey $[\underline{4}, \underline{5}]$. In one study measuring on-ice forces during speed skating, a custom-made force transducer was inserted between the skating boot and the blade []․ Due to the intricacy of figure skating jumps, adding weight and height to a skater's boot could markedly change their ability to perform these skills. Other researchers measured forces experienced by ice-hockey skaters using strain gauges attached directly to the blade holder of hockey boots [4]. Although 
the instrumentation carried in a backpack in that study is not practical for figure skaters, their data showed that measuring on-ice impact forces through the use of strain gauges was possible. The complexity of figure skating limits current instrumentation from measuring impact forces. The instrumentation cannot limit skaters' range of motion, substantially change the inertia of their body segments, or alter sensation. A lightweight, low-interference solution is necessary to accurately measure impact forces in the most realistic setting. Therefore, we designed an apparatus that uses strain gauges and a self-contained data acquisition system to measure on-ice reaction forces during figure skating.

\section{Description}

The apparatus consists of a figure skating blade instrumented with strain gauges, Wheatstone bridge circuit boards, and a data acquisition system. While designed to allow the capability of measuring forces in horizontal and vertical directions, for purposes of this study, only vertical strain, and thus force, was assessed.

\subsection{Figure skating blade and strain gauges}

Measuring forces with strain gauges requires a minimum amount of detectable strain. Traditional figure skating blades are usually made from a single piece of metal such as carbon steel which has a relatively high modulus of elasticity $(E=210 \mathrm{GPa})$. The strain in the stanchions produced by an average skater in a standing posture is on the order of 10 microstrains (for a stanchion height of $2 \mathrm{~cm}$, this corresponds to a compression of less than a micrometer). For a resolution on the order of one tenth of the skater's weight, the strain is only 1 microstrain, which is at the limit of what is detectable with strain gauges in a practical manner. Hybrid blades have a blade holder made from a lighter and more ductile material and therefore compress more. Accordingly, we instrumented a Matrix Legacy (Jackson Ultima) hybrid blade with Aluminum 7005 stanchions (weight $186 \mathrm{~g}$ instead of $227 \mathrm{~g} ; E=72 \mathrm{GPa}$ ), as shown in figure $\underline{1}(a)$. Despite thicker stanchions, the hybrid skate still exhibits $33 \%$ more strain in the stanchions than the traditional blades. 


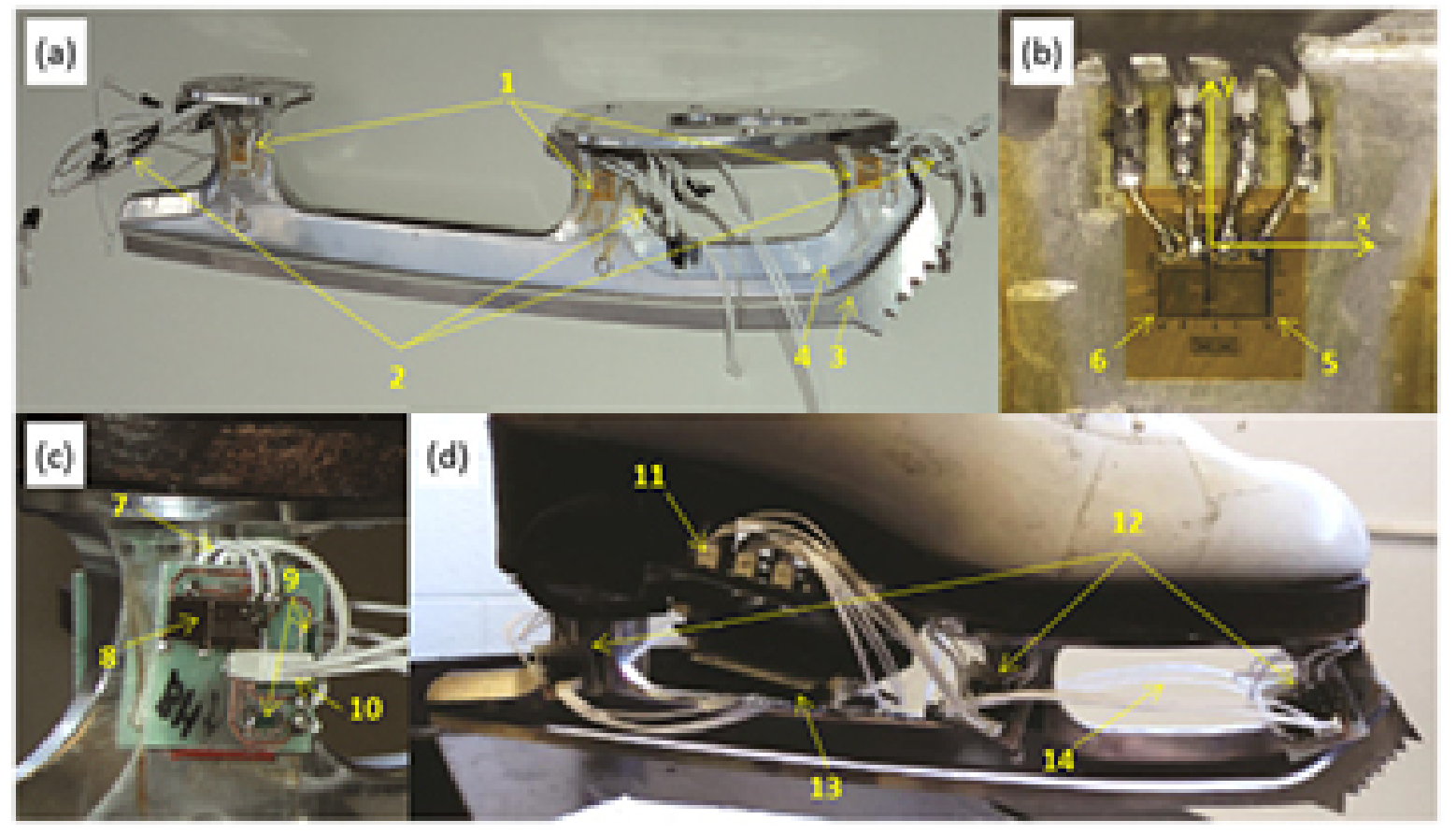

Figure 1. (a) Hybrid skate with strain gauges and wires leading from gauges to Wheatstone bridge boards (not shown): 1, strain gauges; 2, wires to Wheatstone bridge boards; 3, steel blade; 4, aluminum blade holder. The other side of the skate has three sets of gauges as well. (b) Strain gauge; soldering pad; and wires up close: 5 , grid 1 ( $x$-axis); 6 , grid 2 ( $y$-axis). The soldering pad provides a larger surface for more reliable soldering. $(c)$ Wheatstone bridge board: 7 , wires from strain gauges; 8 , potentiometer; 9 , resistors; 10, wires to signal conditioning board (SCB). (d) Integrated system: 11, SCB; 12, Wheatstone bridge boards; 13 , data logger with compact flash card; 14, space for battery.

Download figure:

We applied a set of strain gauges (350 $\Omega$ EA-13-062TT-350 gauges by Micro-Measurements) to each side of each of the three stanchions (figures $1(a)$ and $(b)$ ). Each set of gauges consisted of two electrically independent grids (area $\approx 3 \mathrm{~mm}^{2}$ ) arranged perpendicular to each other on the same polyimide backing in a tee rosette formation [6]. The sets of gauges were mounted in the middle of each stanchion and oriented in such a way that each gauge was aligned with either the vertical or horizontal axis of a datum established by mounting the skate to a board. This ensured that all sets of gauges were aligned with each other and with the vertical and horizontal axes of the back and middle stanchions. The constantan foil of the gauges was chosen to have a coefficient of thermal expansion $\left(13 \mathrm{ppm}^{\circ} \mathrm{F}^{-1}\right)\left(23.4 \mathrm{ppm}^{\circ} \mathrm{C}^{-1}\right)$ close to that of the stanchions $\left(13 \mathrm{ppm}^{\circ} \mathrm{F}^{-1}\right)$ to minimize effects due to changes in temperature. The specific methods used to apply the strain gauges, including preparing the surface, bonding the gauges, and hermetically sealing the gauges (to protect against ice water), are described in [7]. 


\subsection{Wheatstone bridge circuits}

The strain gauges were wired into half-active Wheatstone bridges on surface-mount printed circuit boards (figure $1(c)$ ). Gauges with the same orientation (vertical or horizontal) from each side of a stanchion were wired into the opposite legs of a bridge (figure 2), resulting in six bridges. The remaining legs were completed with passive thin film resistors ( $350 \Omega \pm 0.1 \%$, size $3216 \mathrm{M}$ ). This arrangement cancels strain due to bending while leaving the bridge sensitive to strain aligned with the grid pattern (horizontal and vertical directions). Because of tolerances in the strain gauges and resistors, and because of differences in the lengths of the wires connecting the gauges to the bridges, the initial offset for each bridge was not zero (up to $500 \mu \mathrm{V}$ ). We reduced this offset to less than approximately $5 \mu \mathrm{V}$ using a potentiometer $(10 \mathrm{k} \Omega, 11$ turns, Copal SM-42TA103) and stabilizing resistor (301 $\mathrm{k} \pm 0.1 \%)$ added to the Wheatstone bridge (figure 2). If the offset was too large to be removed by the potentiometer, we added additional resistors (1-105 $\mathrm{k} \Omega \pm 0.1-1 \%$ ) on either side of the potentiometer.

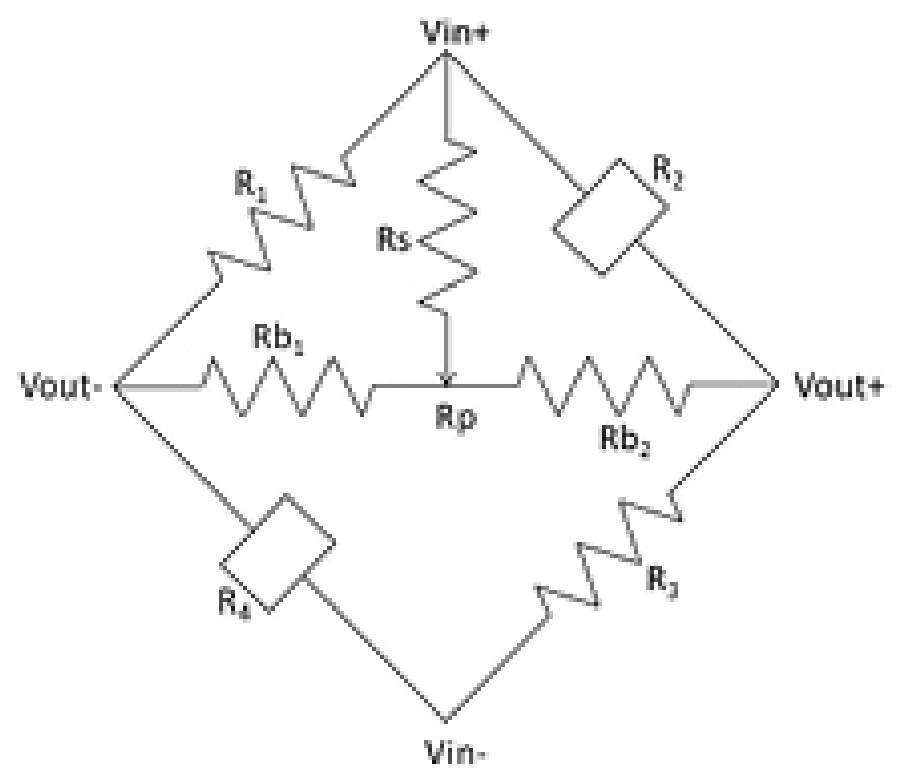

Figure 2. Diagram of Wheatstone bridge boards. The strain gauges are represented as $R_{2}$ and $R_{4}$, with constant resistors $R_{1}$ and $R_{3}$ completing the other legs of the bridge. The potentiometer $\mathrm{Rp}$, stabilizing resistor $\mathrm{Rs}$, as well as resistors $\mathrm{Rb}_{1}$ and $\mathrm{Rb}_{2}$ were added to zero the offset (see section 2.2).

\subsection{Data acquisition system}

The output of each Wheatstone bridge circuit board was wired to the six input channels of a custom-made signal conditioning and data logging system (PSG and Associates, Redlands, CA). This system, which included a 16-bit microcontroller, user control interface, and precisionregulated excitation power supply for the Wheatstone bridge circuits, amplifies the voltage signal from each of the six Wheatstone bridges, passes the signals through an anti-aliasing low-pass filter, with a sampling frequency of at least $1000 \mathrm{~Hz}$, and digitizes them using a 16-bit analog-todigital converter. The digitized signals are stored on the system's Compact Flash memory card. A 
three-way switch turns power on/off and starts/stops data logging. The dimensions of the system are approximately $35 \mathrm{~mm}$ by $50 \mathrm{~mm}$ by $73 \mathrm{~mm}$.

\subsection{System integration}

The Wheatstone bridge circuit boards were attached to the stanchions, and the battery $(7.4 \mathrm{~V}$ $900 \mathrm{mAh}$ Li-polymer battery by OnlyBatteryPacks, Sussex, WI) supplying power to the data acquisition system was mounted in the front open space of the skate (figure $1(d)$ ). The data acquisition system was mounted to a thin, cantilevered bracket compressed between the heel of the boot and the heel plate of the blade. The entire system (including the battery) weighed $142 \mathrm{~g}$ and fit under the boot in the space bounded by the blade and the sides of the boot so that none of the components touched the ice, even when the boot was laid on its side.

\subsection{Calibration}

We performed two different calibration procedures. First, we implemented a static calibration on a manually-operated axial compression apparatus, followed by a least-squares linear regression to create equations for force as a function of strain gauge output. The instrumented blade was mounted to a boot containing a model (ABS plastic) of the human foot and lower leg. The model was cast in the boot for optimal fit, and the boot was laced tight around the model foot and ankle. We stood the model-boot-blade system on a horizontal surface, with the blade parallel to the surface, and applied 14 vertical loads between 0 and $236 \mathrm{~kg}$ to the model leg. Sufficient time (approximately $30 \mathrm{~s}$ ) was allowed to reach static equilibrium and provide sufficient data for averaging. Voltage was continuously recorded at $1000 \mathrm{~Hz}$. Strain gauge output was averaged over 17-26 s for each channel and load and inputted into a linear least squares regression model. The relationship between the known and predicted vertical force from the regression equation was found to be highly linear with $R>0.99$ and root mean square (RMS) error of $0.4 \mathrm{~N}$. Second, we performed a dynamic calibration using a drop landing onto a force plate (OR-6, AMTI, Watertown, MA). An experienced skater wearing figure skating boots, with the right blade instrumented, stood on a $19.8 \mathrm{~cm}$ box and dropped backwards onto the force plate, landing on her right blade. The skater was instructed to land flat on the blade keeping the vertical axis of the stanchions aligned with the vertical axis of the force plate. Force plate data were collected at $1000 \mathrm{~Hz}$ using ViconNexus (Vicon, Centennial, CO) and strain gauge data were collected from the instrumented blade at $1000 \mathrm{~Hz}$. The data from the force plate and instrumented blade were synchronized at initial contact and cropped from $0.05 \mathrm{~s}$ before contact to $0.5 \mathrm{~s}$ after contact. Despite the flat drop landing, small horizontal (anterior-posterior) forces occurred to arrest horizontal momentum. Accordingly both vertical and horizontal (anterior-posterior) forces from the force plate were entered into the linear least squares regression model with the voltage signals from the six strain gauge channels from the instrumented blade.The correlation between the vertical forces from the force plate and the instrumented blade had an $R$-value of 0.96 and RMS error of $128 \mathrm{~N}$.

\subsection{Validation}

The two calibrations were cross-validated using a second drop landing onto the force plate. The least squares model created from the static calibration (static LSQ) and dynamic calibration (dynamic LSQ) were used to compute the vertical force from the landing. These predicted forces were then synchronized at initial contact with the recorded forces from the force plate. Linear 
regressions were computed between the predicted and measured force data from the instant of impact to $0.5 \mathrm{~s}$ following impact. Time to peak force and peak force were determined for Fz1 and Fz2 (1st and 2nd impact peaks respectively, figure $\underline{3}$ ) from the predicted and measured forces.

\section{(a)}

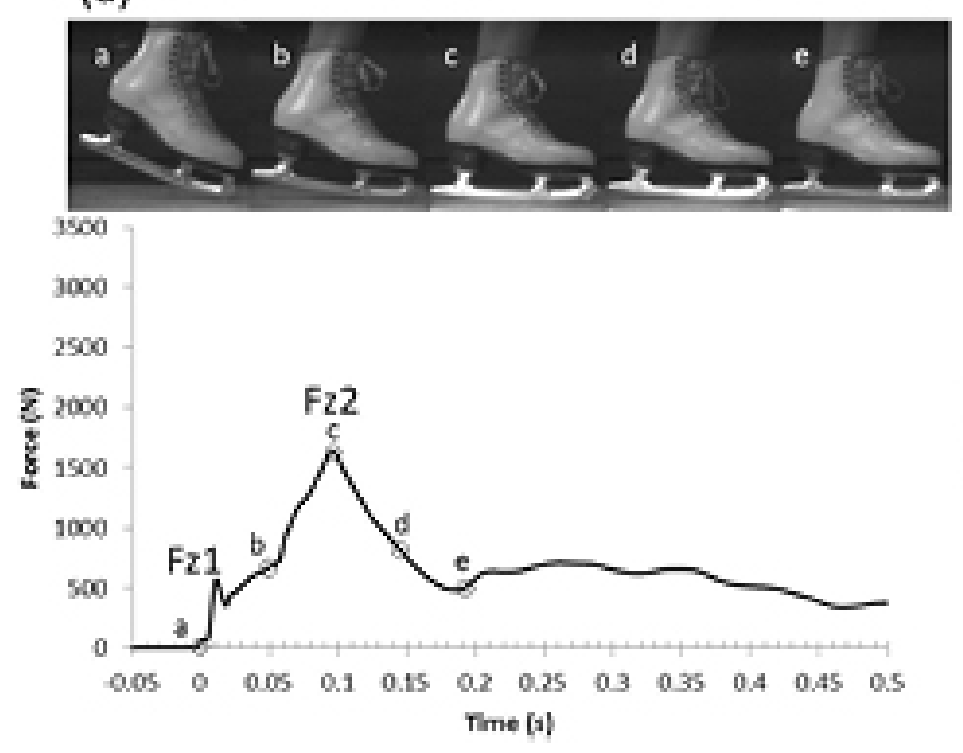

\section{(b)}

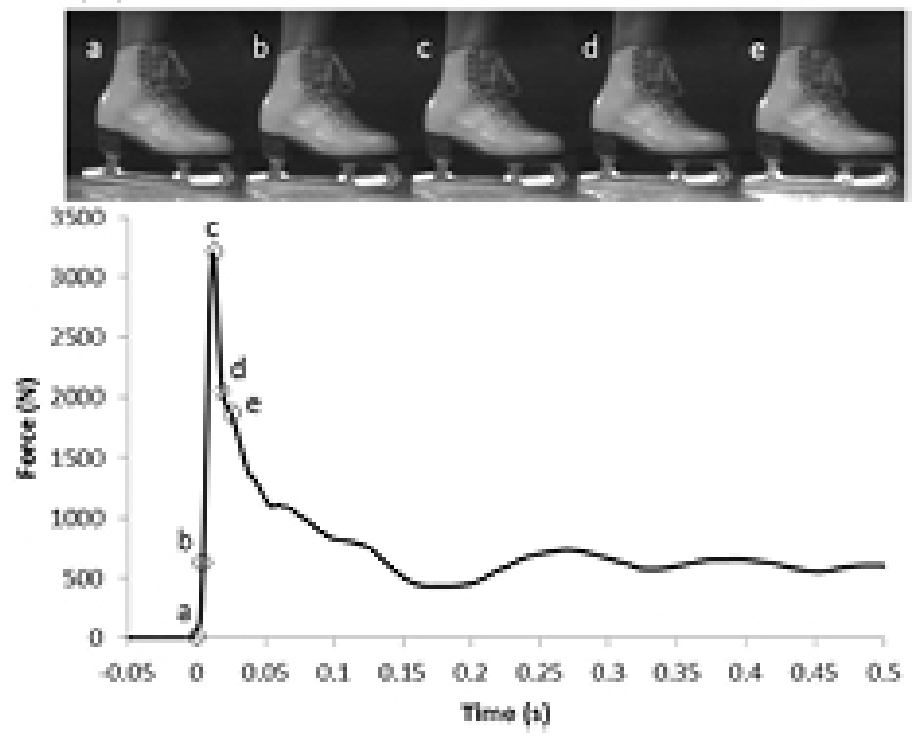

Figure 3. Landing force curves, measured on a force plate, showing (a) initial impact peak, Fz1, followed by second impact peak, Fz2, for a toe-heel landing and $(b)$ one peak force for a flat landing. Corresponding images are from high speed camera (500 fps) synchronized with the force plate. Force data were collected at $2000 \mathrm{~Hz}$ and low pass filtered at $150 \mathrm{~Hz}$. In panel (a) the peak force occurred $0.096 \mathrm{~s}$ after contact and images are shown at $0.048 \mathrm{~s}$ intervals. In panel $(b)$ peak force occurred at $0.012 \mathrm{~s}$ and images are shown at $0.006 \mathrm{~s}$ intervals. The larger quicker peak with the flat landing occurs due to changes in the motions of ankle, knee, and hip when executing a flat landing as opposed to a toe-heel landing resulting a 'stiff' or 'hard' landing.

\section{Results}

\subsection{Static LSQ}

Force data from the cross-validation landing are provided in figure 4 . The magnitude of Fz1 was $1337 \mathrm{~N}$ higher and occurred $1 \mathrm{~ms}$ earlier, measured with the blade as compared to the force plate. The magnitude of Fz2 was $344 \mathrm{~N}$ higher and occurred 2 ms earlier, measured with the blade as compared to the force plate. Prior to impact, the instrumented blade averaged $270 \mathrm{~N}$ while unweighted in the air. After landing, during $0.45 \mathrm{~s}$ of standing on the force plate, the blade measured $206 \mathrm{~N}$ higher than the force plate. 


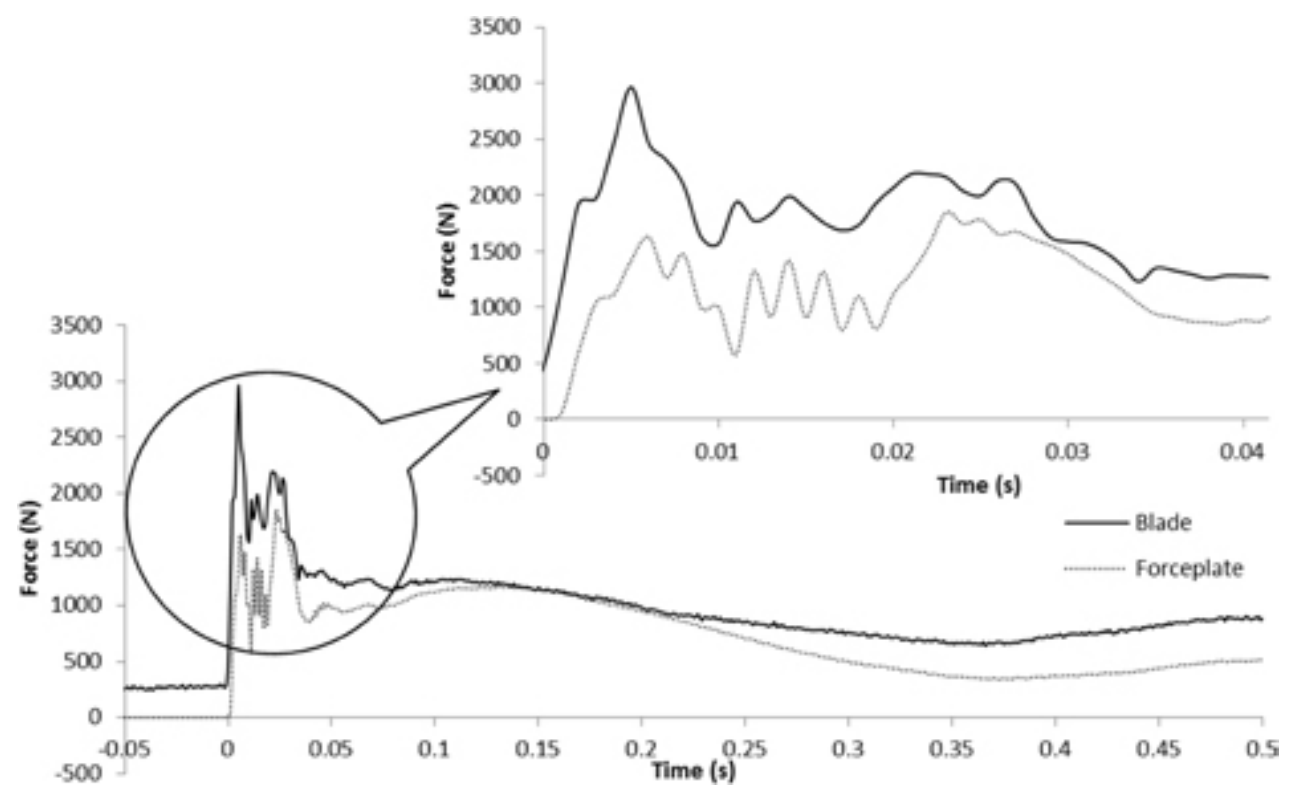

Figure 4. Landing force curves measured with the instrumented blade and force plate using the static LSQ.

Download figure:

\subsection{Dynamic LSQ}

Force data from the cross-validation landing are provided in figure $\underline{5}$. The correlation coefficient ( $R$-value) between the blade and force plate data was 0.88 . The magnitude of Fz1 was $780 \mathrm{~N}$ higher measured with the blade as compared to the force plate. Fz1 occurred at the same time with both the blade and force plate. The magnitude of Fz2 was $20 \mathrm{~N}$ higher and occurred $4 \mathrm{~ms}$ earlier measured with the blade as compared to the force plate. Prior to impact, the instrumented blade averaged $-128 \mathrm{~N}$ while unweighted in the air. After landing, during $0.45 \mathrm{~s}$ of standing on the force plate, the blade measured $133 \mathrm{~N}$ less compared to the force plate. 


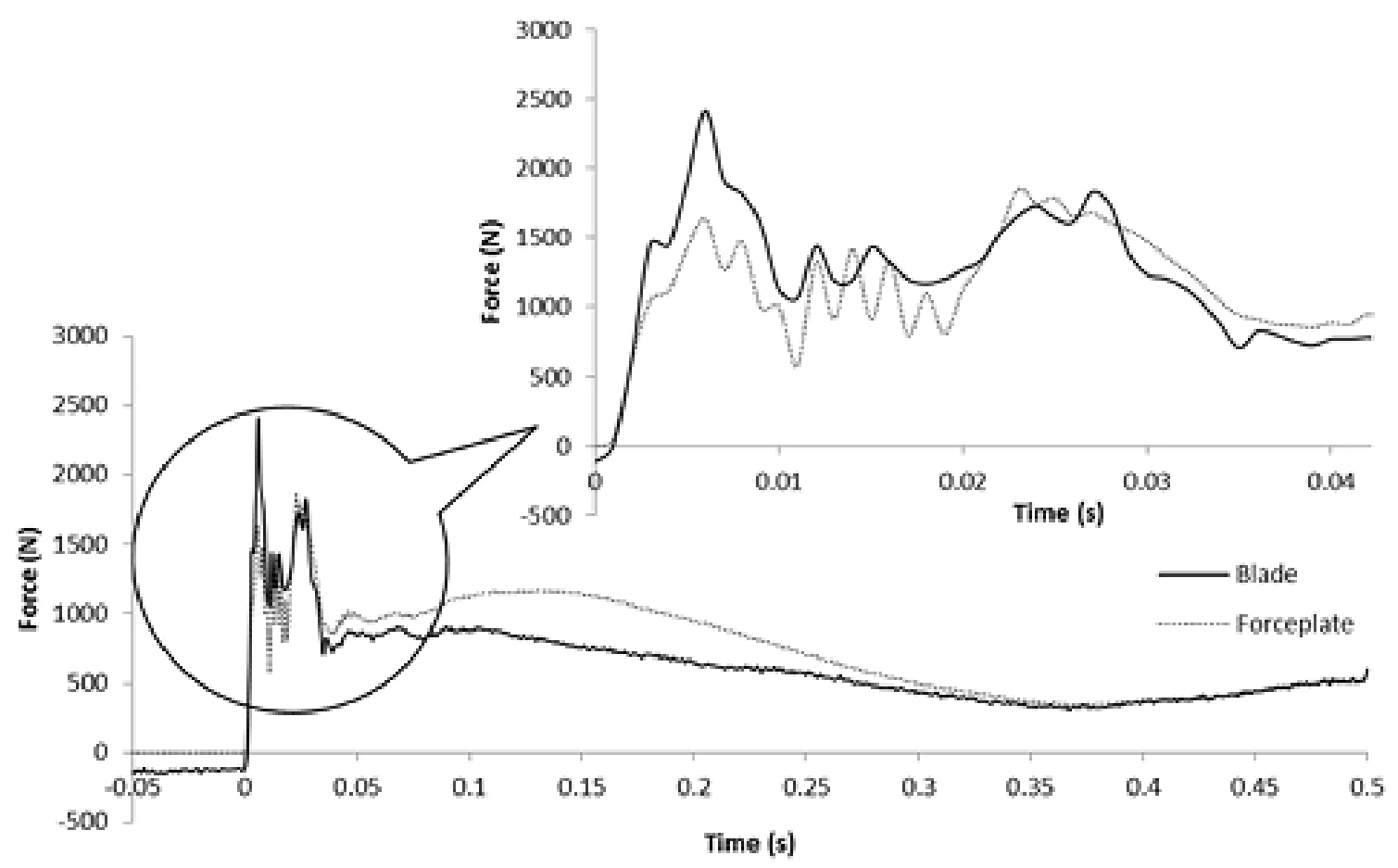

Figure 5. Vertical landing force curves measured with the instrumented blade and force plate using the dynamic LSQ.

\section{Discussion and conclusion}

Using force plates as a gold standard for comparison, this system is effective for measuring forces, though not without its limitations. Both the static and dynamic calibration provided excellent $R$-values between the predicted and actual loads similar to those of Stidwill et al [4]. The RMS error for the static calibration was less than $1 \mathrm{~N}$, though the prediction accuracy dropped when applied to a cross-validation jump. Although the $R$-value was still good (0.82) for the static calibrated cross-validation jump, the differences in magnitude of the important peaks were larger than with the dynamic calibration. High speed video revealed small changes in blade angle during the landing of the cross-validation jump. These non-zero blade angles and dynamic loading rates may have contributed to the reduction in accuracy for the Static LSQ crossvalidation landing. Stidwill et al [4] reported a small dependence on loading rate in their straingauge instrumented hockey blade.

The dynamic cross-validation resulted in measurements from the blade that were more similar to those obtained from the force plate than when using the Static LSQ. Our correlation values $(R-$ value $=0.88$ ) between the data from the force plate and from the blade demonstrate the effectiveness of the system. In addition to fairly good agreement between force magnitudes, the timing of the peak values was similar between the two methods of measurement. However, the difference in force magnitude was greater for Fz1 as compared to Fz2, possibly due to non-zero blade angles at initial contact in both the calibration and cross validation landings. Due to the difficulty in landing perfectly flat on the blade, measuring blade angle during the dynamic 
calibration so that a coordinate transformation can be performed is likely necessary for improved accuracy.

Moreover, for the dynamic calibration, the horizontal forces were entered into the regression model. However, due to the small horizontal forces, the strain in the horizontal direction may not have been sufficient to be measured accurately. One of the greatest difficulties with measuring forces on a figure skating blade is the relatively high modulus of elasticity of the blade. Even with the aluminum blade holder, the amount of strain measured for a desired resolution of one tenth of the skater's body weight is on the order of one microstrain (less than 1 micrometer for a stanchion height of $2 \mathrm{~cm}$ ), which is at the limit of what is measurable with current strain gauge technology, especially with instrumentation that has to fit under the boot. It is possible that data from more than one landing and with greater horizontal strain is needed to create a more robust calibration for the Dynamic LSQ. For comparison, Stidwill et al used 30 trials of multiple vertical loads and loading rates accompanied by separate medial and lateral loading for their calibration [4]. Their paper did not report cross-validation results with non-calibration loading trials, so it is not possible to compare the prediction accuracy observed in the current study to that of Stidwill et al [4].

However, as currently constructed, this system is capable of measuring vertical forces during simulated figure skating landings. The design of the system allows it to be unobtrusive to figure skaters as they perform their typical repertoire of jumps, spins, and footwork. Horizontal force can be measured by adding horizontal loading to either the dynamic or static calibration. Further development of this system will result in increased resolution and accuracy of the measurements.

\section{Acknowledgments}

We'd like to thank Jim Johnson (Micro-Measurements, Wendell, NC) for technical assistance with strain gauges, Jacquelyn Packard for figure skating consulting, and Jacquelyn Packard and Catherine Summers for performing the jumps used in the calibration and validation. Co-author $\mathrm{P}$ Starbuck is inventor of the data acquisition system used in this paper and owner of a company that designs and sells similar systems for other applications.

\section{References}

1. Bruening D A and Richards J G 2006 The effects of articulated figure skates on jump landing forces J. Appl. Biomech. 22 285-95

2. Pecina M, Bojanic I and Dubravcic S 1990 Stress-fractures in figure skaters Am. J. Sports Med.18 277-9

3. Lockwood K L and Gervais P L 1997 Impact forces upon landing single, double, and triple revolution jumps in figure skaters Clin. Biomech. 1211

4. Stidwill T, Turcotte R, Dixon P and Pearsall D 2010 Force transducer system for measurement of ice hockey skating force Sports Eng. 12 63-8

5. Jobse H, Schuurhof R, Cserep F, Schreurs A W and Dekoning J J 1990 Measurement of push-off force and ice friction during speed skating Int. J. Sport Biomech. 6 92-100

6. Micro-Measurements 2013 Strain gage rosettes: selection, application, and data reduction Strain Gages and Instruments Technical Note TN 515 www.vishaypg.com/docs/11065/tn-515.pdf

7. Micro-Measurements 2013 Surface preparation for strain gage bonding Bonding Instruction Bulletin B-129-8 www.vishaypg.com/docs/11129/11129 b1.pdf 